\title{
System availability study results in the example of radio com- munication system in the underground mine
}

\author{
Batzorig Bazargur ${ }^{1}$, Otgonbayar Bataa ${ }^{2}$ and Uuganbayar Budjav ${ }^{2, *}$ \\ 1 Mongolian university of science and technology, School of Information communication and technology; \\ batzorigbazargur@gmail.com \\ 2 Mongolian university of science and technology, School of Information communication and technology; \\ otgonbayar_b@must.edu.mn \\ * Correspondence: Mongolian university of science and technology, System thinking laboratory. buuga- \\ naa@must.edu.mn.
}

\begin{abstract}
The availability rating of any system is the probability that it will be able to operate for a given time in other words, to restore the system in the case of a system failure, or during the failure it is a measure of the availability index of resource system. We aimed to complete the study for the reasons as below. The rating and upgrading of underground mine radio communication system availability is to ensure operation reliability of the underground mine and to establish reliable radio communication system for miner's safety during failure. Therefore, our study is contributed to reveal system availability rating of single resource (with two parallel connections) system and two resources (with three parallel connections) system. The study is related to not only practical contribution but also reliability engineering theory. To achieve this result, we have used Exponential, Weibull, and Poisson distributions. The readiness rating of single resource (with two parallel connections) and two resources (with three parallel connections) systems were calculated using Matlab software and the simulation results were introduced. This result confirms that any system has a resource system, which increases its readiness rating. The study was in examples of single resource radio communication system on the two shafts of the underground mine and two resource radio communication system for three shafts. During the initial system reliability enhancement study, the readiness of the dual resource system was assessed. The rating shows a 99 percent result, which is very meaningless for systems with more than two n-resources and we have revealed that it can show more than 100 percent result. In the process of the study on system reliability improvement the rating availability of system which has two resources was $99 \%$ result. It is very meaningless for systems with more than two n-resources or more than $100 \%$ result.
\end{abstract}

Keywords: Distribution, Availability, Analysis

\section{Introduction}

Availability is function measurement of system that expresses availability probability of used system in any instant case. In addition to this availability is probability that system possible works during given $t$ time. This is shown repair maintenance and reliability also if there is need system can be worked or predicted it ready to work [1]. We have estimated mentioned in the paper differential equations. In the paper [1] they have estimated bivariate Weibull distribution and have shown results of availability function which was developed by Maple program.

In the case failure of radio communication system in underground mine without any resources, there is a risk that miners inside the underground mine will not be able to communicate with the on-site control room and other parts.

In other words, the reliability of a radio communication system without any resources is always low.

The main causes of radio communication failure in underground mine are usually power failure, followed by faults depending on the design and system characteristic of 
the radio communication system operating in the underground mine, such as broken optical and radiation cables, damage to repeaters in underground mines, and interference, excessive length of the radiation cable, changes in the core system, repair work, etc.

If the radio equipment inside the underground mine is connected to the surface site by a single gateway, it will be less reliable, as mentioned above, and if it has two or three gateways (shafts) will increase the availability probability of underground radio communication readiness as shown by the study.

We have theoretically proven that it is possible to achieve a radio readiness level of up to $99 \%$.

Manufacturing standard requirements must meet the requirements of ITU-T P.800 and TIA TSB88-A.

The paper is part of my doctoral dissertation which is related to the study of factors affecting the reliability of underground mining operation.

Therefore, we have introduced here the results of probability of readiness study on communication system with single and two resources.

This time we have improved availability more than in the previous paper and have estimated two and three parallel Exponential, Weibull, Poisson distribution and have resulted availability function which was developed by Matlab program. Before we have classified natural, underground mining itself and mining radio communication system's risks that can be affected on availability of underground mining radio communication system. We have chosen earthquake from those and have approximately estimated risk probability of earthquake [2]. However, we have done it using data and information about earthquake which was occurred in the Oyu Tolgoi mine which is located in Umnugovi aimag in the south of Mongolia. In the future work we will approximately estimate and classify disaster risk that can be occurred in the above-mentioned underground mine. Whereas in the [3], we have estimated failure rate of underground mining communication system's reliability function using four different functions and we have suggested an idea on Exponential distribution theory is improved system's reliability probability.

Dolas, Jaybhaye, and Deshmukh have estimated the system reliability using Weibull distribution with two parameters in the work [4]. Diesel engine operation time without failure was estimated using lifetime $(\boldsymbol{\eta})$ and system's state coefficient measurement in the examples of diesel engine.

Sigeo Aki and Katuomi Hirano are considered that the system's lifetime is independent, and it has same distribution and the results were estimated parameters of all possible problems based on the system's life-time analyses. [5]. Lai and Min Xie were introduced to new model function of the system's life-time distribution. They were easily estimated Weibull probability using Weibull distribution with 3 parameters and they compared it with other Weibull distribution models [6]. Researchers Ming Dong and Alexandre B.Nassif were estimated power system reliability forecast in the examples of power system in the western Canada using different Weibull distribution models which wasn't used before [7]. Maurice Aron, Neila Bhouri and Younes Guessous were introduced to results of travel time distribution for reliability analysis in their paper. They compared 6 different statistical distributions to each other's in their study. They used normal distribution Gamma, Burr, and Weibull, mixed and Gamma mixed distributions for these 6 distributions. From those mixed and Gamma mixed distribution probability results and test results were approximate [8]. In the paper by Mouloud Guemana, Ahmed Hafaifa and Ben Rahmoune Mohamed were estimated reliability modeling using Rayleigh Distribution for estimation and design of industrial pump's reliability parameter [9]. Like this paper in another paper completed by Ahmed Hafaifa, Kouzou Abdellah, Guemana Mouloud and Nadji Houdrug was discussed reliability analyses of booster pump which was used in oil drilling installation based on reliability analysis. Researchers used reliability analyses by Weibull's distribution with 3 parameters in the study [10]. Damcese studied reliability equivalence factors of a series-parallel system in Weibull distribution and used 3 different to each other's methods (minus, hot resource, and cold resource) to improve reliability of system [11]. 
Stylianos Georgiadis and Nicolaos Limnios studied system which is in finite space. They studied interval reliability for semi-Markov systems in discrete time [12].

Moreover Olga Rahneva, Hristo Kiskinov, Ivan Dimitrov and Viktor Matanski included in their study application of a Weibull cumulative distribution function based on $\mathrm{m}$ existing. The results of the study have shown significance of problems related to study life-time analyses, insurance mathematics, biochemical kinetics, population dynamics and correct failure [13].

Also S.K.Chauhan and S.C.Malik included repair time of the system failure connected in series to " $\mathrm{n}$ " components and reliability measures of a series system with Weibull Failure Laws and these results predicted using Rayleigh failure law as special version [14]. Coolen in his paper studied basic characteristics of reliability model distribution which is for special case. In other word predicted parametric model was approved by reliable statistics extraction [15].

Thanh Pham Hong and Nguen Hoang Viet introduced to new method to review and to compare power system design based on factors such as safety, price, repairing possibility of generators for power system and based on complex result of reliability [16]. Chen Wenhua, Qian Ping, Cui Jie, Ma Zikui, Gao Liang and Liu Juan have shown estimation of reliability analysis of data only one failure for $\boldsymbol{\beta}$ distribution using Beis's stepped method [17]. Zhao Fei, Huang Ning and Chen Jiaxi summarized and classified distribution regime of communication chain point distribution. When study result was with limited expenses it was the chain reliability design and reliability simulation result [18]. But Raja Sattiraju, Pratip Chakraborty and Hans D. Schotten dealt with renewed process as repair index $(\mu)$ and wireless transmission case failure $(\lambda)$ and have shown reliability modeling and analyses of a wireless transmission as a repairable system [19]. Ismihan Bairamov's paper considers the joint distribution of elements of a random sample and an order statistic of the same sample. The motivation for this work created from the important problem in reliability analysis, to estimate the number of inspections he needs to detect failed components in a coherent system. [20]. In this paper we have shown analyses of 3 equipment communication system to distribute load connected parallel. We have estimated equipment failure and repairing functions by two and three parallel, Exponential, Weibull, and Poison distribution. Also, availability of system and probability of stable state were studied, and repair time of reliability and failure was introduced.

\section{Materials and Methods}

Availability of Communication system (it is same as Power system) is depended on natural and human factors. Our goal is not to study reason of the accident and we are trying to find a way how to improve operation availability. One of the ways to improve is to install more Communication system. We will study improvement availability of all systems for connection two and three communication systems in parallel situation by establishing mathematical structure. Availability is probability of system operating possibility in given $t$ period. There is included both repair period of the operation until next failure and repairing and improving time. Reliability is quantitative function amount of the operation. In other words, it is resulted to measure possibility to complete the operation in certain situation and in appropriate time.

\section{Availability of two-parallel communication system}

This The system is consisting of two communication equipment which are connected parallel and it is operated as undefended on each other's. We considered if there is failure in the equipment it would not influence to other equipment. The system is divided into 4 states and the states $(0,0) ;(1,0) ;(0,1)$ are operating states and the state $(1,1)$ is failure state. In the figure 1 is shown all possible states between them and transitional variance.

The system is modeling as next four regular differential equation systems.

$$
\frac{d P_{t}[0,0]}{d t}=-\left[\lambda_{1}(t)+\lambda_{2}(t)+\lambda_{5}(t)\right] P_{t}[0,0]+\mu_{1}(t) P_{t}[1,0]+\mu_{2}(t) P_{t}[0,1]+\mu_{5}(t) P_{t}[1,1]
$$




$$
\begin{aligned}
& \frac{d P_{t}[1,0]}{d t}=-\left[\lambda_{3}(t)+\mu_{1}(t)\right] P_{t}[1,0]+\lambda_{1}(t) P_{t}[0,0]+\mu_{3}(t) P_{t}[1,1] \\
& \frac{d P_{t}[0,1]}{d t}=-\left[\lambda_{4}(t)+\mu_{2}(t)\right] P_{t}[0,1]+\lambda_{2}(t) P_{t}[0,0]+\mu_{1}(t) P_{t}[1,1] \\
& \frac{d P_{t}[1,1]}{d t}=-\left[\mu_{4}(t)+\mu_{3}+\mu_{5}(t)\right] P_{t}[1,1]+\lambda_{5}(t) P_{t}[0,0]+\lambda_{3}(t) P_{t}[1,0]+\lambda_{4}(t) P_{t}[0,1]
\end{aligned}
$$

Primary situation of system was given as:

$$
P_{0}[0,0]=1, P_{0}[1,0]=0, P_{0}[0,1]=0, P_{0}[1,1]=0
$$

To solve these kinds of tasks first must detect failure function and repairing function on what failure law is governed by. The indices should be governed by Weibull, Exponential, and Poisson distributions law and let's estimate the modeling in separate situation for each one. If there is quantitative data, we would estimate by establishing distribution law and by checking prediction on distribution law form. We haven't any real data therefore we will estimate using abstract quantities. At present time techniques and technology maintenance and its safety, reliability is required from the engineers to invent many complex systems depended on reliability of different components which are composed the system. For example: to burn out safety fuse, to bend steel rod, to lost reliability of heat sensor equipment. Also, same components in the same environment can be run out in unpredicted different period. Weibull distribution, Exponential distribution and Poisson distribution are widely used to solve these problems.

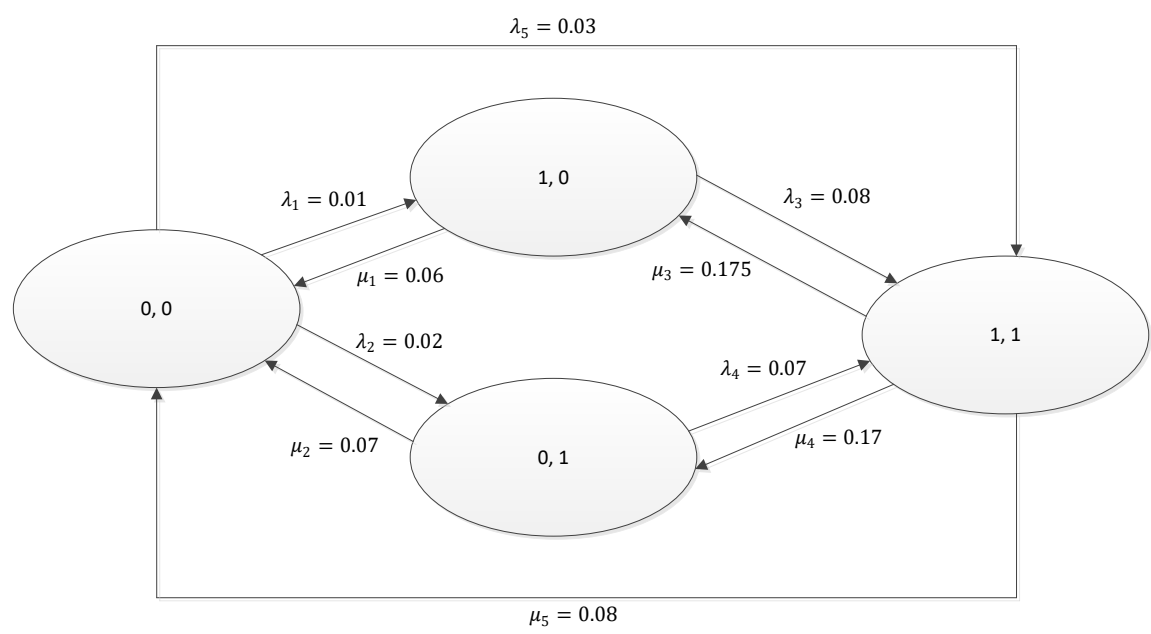

Figure 1. Two parallel communications system.

Figure 1 shows a single resource communication system or two-parallel operating communication systems. In terms of reliability theory, these two functions were chosen because they represent as $\lambda$ -failure function meaning and the $\mu$-correction function meaning. Figure 1 shows that the system is in four states of function. In other words, the time-dependent Weibull, Poisson, and Exponential distributions were developed using differential equations. The $\lambda$ and $\mu$ functions are limited to between 0 and one, or the failure and repairing probability functions.

\section{Weibull distribution:}

Density function of Weibull distribution is determined by the formula:

$f(t, \alpha, \beta)=\frac{\alpha}{\beta^{\alpha}} t^{\alpha-1} e^{-(t / \beta)^{\alpha}}$

Using some characteristics, we have tried some easy transforming for the formula. 
$\lambda_{i}(t)=\boldsymbol{\beta} \lambda_{i} t^{\beta-1}, i=\overline{1,5}$

$\mu_{i}(t)=\boldsymbol{\beta} \mu_{i} t^{\beta-1}, i=\overline{1,5}$

Availability function is founded by adding operating state of the system.

$$
A(t)=P_{0}[0,0]+P_{0}[1,0]+P_{0}[0,1]
$$

t period of availability function, limit is probability of reliability or reliable operation. In other words, probability of reliable operation can be estimated using the formula.

$A=\lim _{t \rightarrow \infty} A(t)$

Therefore, our final aim is to estimate the above differential equation system and to add functions $P_{t}[0,0]+P_{t}[0,1]+P_{t}[1,0]$ and to estimate A figure as $t$ period limit. We have chosen ode 45 command of the commands as dsolve and ode 45 , ode23 to estimate differential equation system. However, we have chosen dsolve command to estimate for the first time it was too slow and then we have chosen ode 45 command which was quicker to estimate. Generally, you can consider there is no differences for ode 45 and ode 23 commands.

Exponential distribution:

Exponential distribution density function is determined by the formula.

$f(t)=\lambda e^{-\lambda t}$

If we try some easy transforming for the Exponential distribution formula it would be as:

$\lambda_{i}(t)=\lambda_{i} e^{-\lambda_{i} t}, i=\overline{1,5}$

$\mu_{i}(t)=\mu_{i} e^{-\mu_{i} t}, i=\overline{1,5}$

It was $\mathrm{A}=0.6067$ if find reliability probability using code in Matlab and it was same as for estimating Weibull distribution.

Poisson distribution:

Poisson distribution density function

$f(t)=\frac{e^{-\lambda} \lambda^{t}}{t !}$

is determined by the formula. If we try easy transforming for the Poisson distribution formula it would be as:

$\lambda_{i}(t)=\frac{\lambda_{i} b^{t}}{t^{t} \sqrt{2 \pi t}}, i=\overline{1,5}$

$\mu_{i}(t)=\frac{\mu_{i} b^{t}}{t^{t} \sqrt{2 \pi t}}, i=\overline{1,5}$

But Poisson formula can't be strictly tried to put in Matlab. Because Matlab can't consider t! factorial and therefore $t$ ! factorial can be replaced by the below formula to estimate as:

$t !=\sqrt{2 \pi t}\left(\frac{t}{e}\right)^{t}$

The formula is called as Stirling formula. We can try easy transforming for the follow formula as:

It was $\mathrm{A}=0.8988$ if find reliability probability using code in Matlab and it was same as for estimating Weibull distribution and Exponential distribution. 
The above formulas can be used to estimate for three-parallel communication system. Also, for general case the formula can be used.

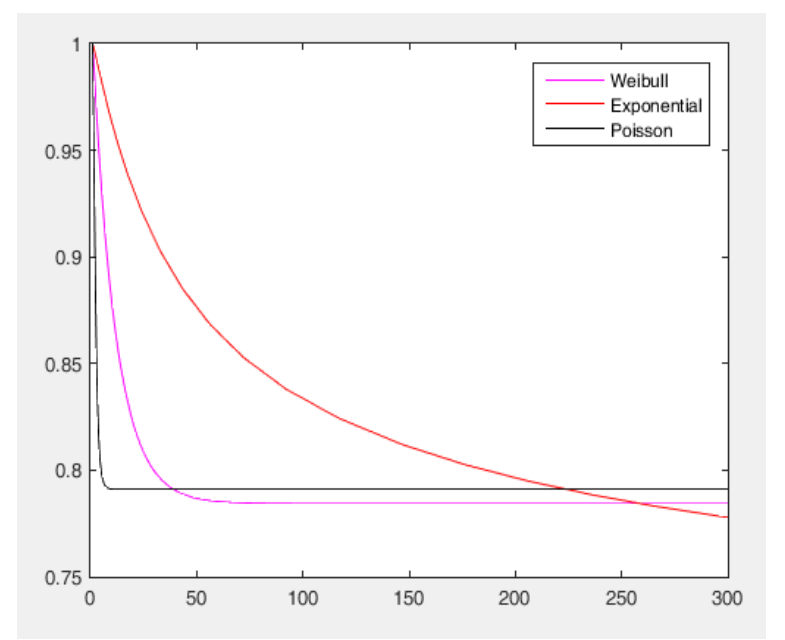

Figure 2. Common graph of Poisson Distribution, Exponential, and Weibull, two parallel radio communication system.

\section{Availability of three parallel communication system}

The system is consisted of three communication equipment in parallel connection and there is no dependence on each other's. We considered if any of the equipment failure it can't affect other ones. The system is determined and divided into 8 states. $(0,0,0)$; $(1,0,0) ;(0,1,0) ;(0,0,1) ;(1,1,0) ;(1,0,1) ;(0,1,1)$ are operating states and $(1,1,1)$ is the state in failure. In the figure are shown all possible states between them and transitional variance. When all equipment is operating without failure one of them can failure it is considered as one of them has failure other one can failure. In other words, two equipment can't be in the same state and first one will be in failure, then the second one will be in failure and the three can be in failure. Also, repair indices are considered same as failure indices. 


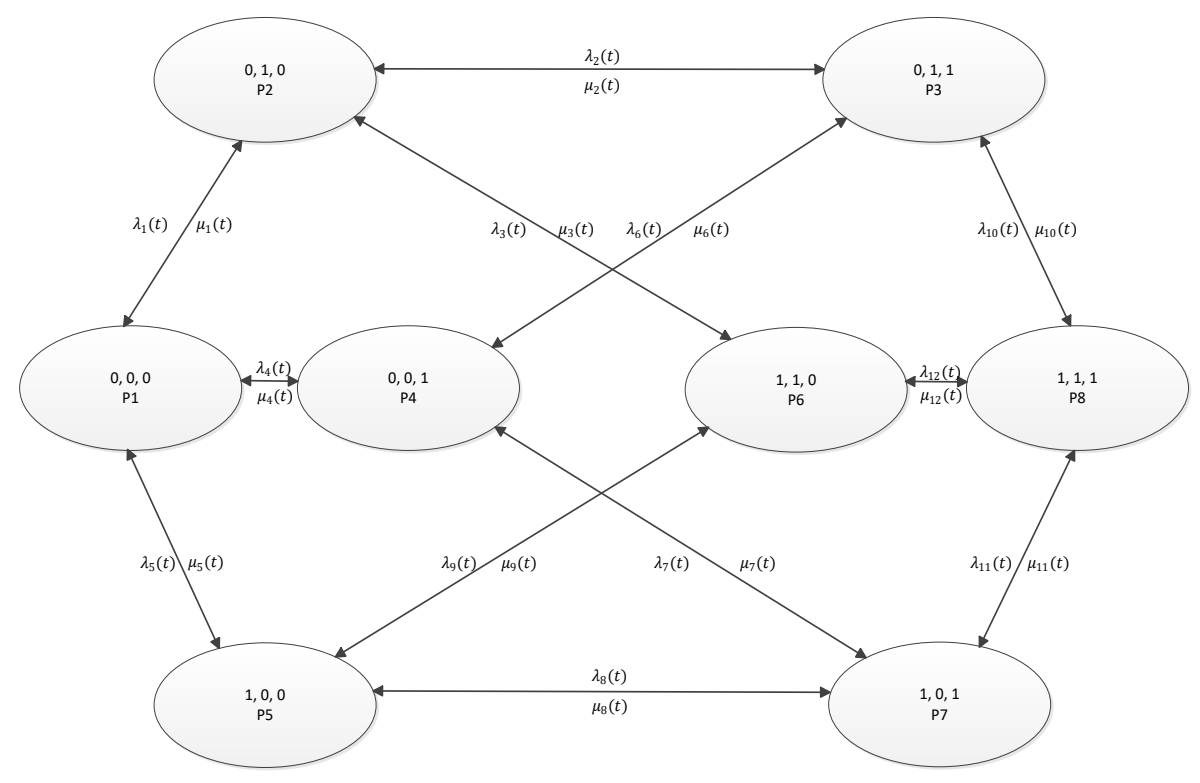

Figure 3. Three parallel communications system.

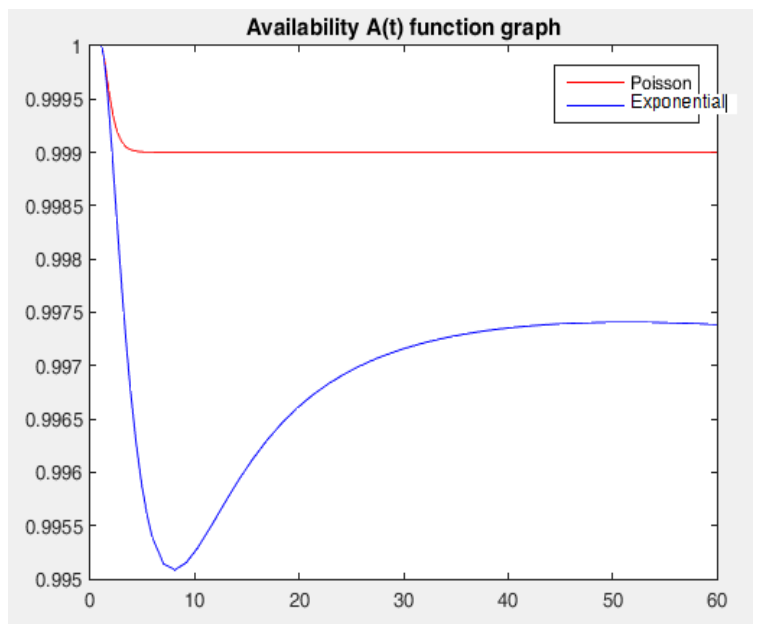

Figure 4. Common graph of three parallel Poisson and Exponential Distribution.

Note: The $\mathrm{x}$-axis shows the lifetime (in years) of the radio communication system, and the y-axis shows the reliability level (in percent).

The system is designed as following typical differential equation system.

$$
\begin{aligned}
& \frac{d P 1}{d t}=-\left[\lambda_{1}(t)+\lambda_{4}(t)+\lambda_{5}(t)\right] P 1+\mu_{1}(t) P 2+\mu_{4}(t) P 4+\mu_{5}(t) P 5 \\
& \frac{d P 2}{d t}=-\left[\lambda_{2}(t)+\lambda_{3}(t)+\mu_{1}(t)\right] P 2+\mu_{2}(t) P 3+\mu_{3}(t) P 6+\lambda_{1}(t) P 1 \\
& \frac{d P 3}{d t}=-\left[\lambda_{2}(t)+\lambda_{6}(t)+\mu_{10}(t)\right] P 3+\mu_{2}(t) P 2+\mu_{6}(t) P 4+\lambda_{10}(t) P 8 \\
& \frac{d P 4}{d t}=-\left[\lambda_{6}(t)+\lambda_{7}(t)+\mu_{4}(t)\right] P 4+\lambda_{4}(t) P 1+\mu_{7}(t) P 7+\mu_{6}(t) P 3 \\
& \frac{d P 5}{d t}=-\left[\mu_{5}(t)+\lambda_{9}(t)+\lambda_{8}(t)\right] P 5+\lambda_{5}(t) P 1+\mu_{9}(t) P 6+\mu_{8}(t) P 7 \\
& \frac{d P 6}{d t}=-\left[\lambda_{12}(t)+\mu_{3}(t)+\mu_{9}(t)\right] P 6+\lambda_{3}(t) P 2+\lambda_{9}(t) P 5+\mu_{12}(t) P 8 \\
& \frac{d P 7}{d t}=-\left[\lambda_{11}(t)+\mu_{7}(t)+\mu_{8}(t)\right] P 7+\mu_{11}(t) P 8+\lambda_{8}(t) P 5+\lambda_{7}(t) P 4
\end{aligned}
$$


$\frac{d P 8}{d t}=-\left[\mu_{10}(t)+\mu_{11}(t)+\mu_{12}(t)\right] P 8+\lambda_{11}(t) P 3+\lambda_{11}(t) P 7+\lambda_{12}(t) P 6$

Primary situation of system was given as:

$$
\begin{gathered}
P 1=0 ; P 2=0 ; P 3=0 ; P 4=1 ; P 5=0 ; \\
P 6=0 ; P 7=0 ; P 8=0
\end{gathered}
$$

Availability function is founded by

$$
A(t)=P 1+P 2+P 3+P 4+P 5+P 6+P 7
$$

and probability availability operation by formula:

$A=\lim _{t \rightarrow \infty} A(t)$

If the distribution law is governed by Weibull, there will be taken as:

$$
\begin{aligned}
& \lambda_{i}(t)=\boldsymbol{\beta} \lambda_{i} t^{\beta-1}, i=\overline{1,12} \\
& \mu_{i}(t)=\boldsymbol{\beta} \mu_{i} t^{\beta-1}, i=\overline{1,12}
\end{aligned}
$$

If the distribution law is governed by Exponential law, there will be taken as equation 10, 11. If the distribution law is governed by Poisson law, there will be taken as equation 13, 14 .

When we have completed the study was faced following problems:

- $\quad$ Failure function $(\lambda)$ of three parallel radio communication system, meanings of repairing function $(\mu)$ were modeled by Weibull distribution law and availability is not matched with regular number. In other words, it was not stable. Therefore, we have left out Weibull distribution for three parallel radio communication system.

- $\quad$ Also for two and three parallel radio communication systems we have tried to identify stability of availability function using differently put as mixed failure function $(\lambda)$ and repairing function $(\mu)$ or put function on failure function $(\lambda)$ and put Poisson on repairing function $(\mu)$, or put Weibull on failure function $(\lambda)$ and put function on repairing function $(\mu)$. But availability function was not stable, and we have not realized this idea.

- When we tested modeling of two or three parallel radio communication systems, we have used dsolve command of Matlab program. This process was too slow for results and then we have chosen ode23 command instead of dsolve command and we have completed the calculation.

- When we considered that meanings of failure function $(\lambda)$ and repairing function $(\mu)$ will be ruled by Poisson distribution law it was difficult to estimate differential equitation system because $t$ ! factorial $(t$ !) was appeared in the formula. Therefore, we have chosen Stirling formula instead of $\mathrm{t}$ ! factorial ( $\mathrm{t}$ !) and have completed the calculation.

When all versions were taken in three parallel radio communication system modeling and in this case differential equitation systems were difficult for recording and calculation therefore, we have passed this case. Particularly, when these three systems are worked all these three systems are put off and we passed it. In other words, firstly the first equipment was cut, secondly the second equipment was cut, and lastly the third equipment was cut. In this case we have modeled these three parallel systems all will be cut.

Supplementary Materials: The following are available online at www.mdpi.com/xxx/s1, Figure S1: title.

Author Contributions: Please turn to the CRediT taxonomy for the term explanation. Authorship must be limited to those who have contributed substantially to the work reported. 
Funding: "This research received no external funding".

Institutional Review Board Statement: “Not applicable."

Informed Consent Statement: “Not applicable."

Data Availability Statement: We haven't used ready data of radio communication system in the study. We have used only randomly chosen data in theoretical frame for the study results.

Acknowledgments: "Not applicable".

Conflicts of Interest: "The authors declare no conflict of interest."

\section{Conclusion:}

We have modeled availability of radio communication equipment which are depended on each other's by three parallel Exponential, Weibull, and Poisson distribution. Exponential, Weibull and Poisson distributions were executed by two-parallel and three-parallel models. We have analyzed results of three communication systems located on the three shafts of the underground mine. In other words, we have used three-parallel distribution to increase availability. Using this three-parallel distribution model we have compared how was improved availability of communication system for the three communication systems located on the three shafts of the underground mine. We haven't used ready data of radio communication system in the study. We have used only randomly chosen data in theoretical frame for the study results. We have modeled our study using exponential, Weibull, and Poisson distributions on Matlab program. Four, five and even up to $n$ redundancy systems have more redundancy systems than three parallel or two redundancy system and meaningless according to theory and practice. It is very difficult to estimate differential equation system and it has no solution or not clear to have solutions. Therefore, in the further the study of any system requires more specific study not general study. Especially, availability of two parallel systems by Weibull distribution was $89 \%$ and exponential distribution was $69 \%$ but by Poisson distribution was $89 \%$ as by Weibull distribution and availability of three parallel systems was $91 \%$ and exponential distribution was $99 \%$ by Poisson distribution and was increased the availability for three parallel systems. In other words, the study results were proved that availability of two redundancy systems is more reliable than one redundancy systems. 


\begin{tabular}{|c|c|c|}
\hline Functions & Reliability of two-parallel communication system & Reliability of three parallel communication system \\
\hline Probability & $\begin{array}{l}P_{t}[0,0]-\text { is probability for operating the system in } t \text { period } \\
P_{t}[1,0]-\text { is probability for failure of the first equipment and for operating of the second } \\
\text { equipment in t period } \\
P_{t}[0,1]-\text { is probability for operating of the first equipment and for failure of the second } \\
\text { equipment in } t \text { period } \\
P_{t}[1,1]-\text { is probability for not operating of the system in } t \text { period }\end{array}$ & $\begin{array}{l}P_{t}[0,0,0]-\text { is probability for operating the system in } t \text { period } \\
P_{t}[1,0,0]-\text { is probability for failure of the first equipment and for operating of the second and } \\
\text { third equipment in } t \text { period. } \\
P_{t}[0,1,0]-\text { is probability for failure of the first and third equipment and for operating of the } \\
\text { second equipment in } t \text { period. } \\
P_{t}[0,0,1]-\text { is probability for failure of the first and second equipment and for operating of the } \\
\text { third equipment in } t \text { period. } \\
P_{t}[1,1,0]-\text { is probability for failure of the first and second equipment and for operating of the } \\
\text { third equipment in t period } \\
P_{t}[1,0,1]-\text { is probability for failure of the first and third equipment and for operating of the } \\
\text { second equipment in } t \text { period. } \\
P_{t}[0,1,1]-\text { is probability for failure of the first equipment and for operating of the second and } \\
\text { the third equipment in t period. } \\
P_{t}[1,1,1]-\text { is probability for not operating of the system in t period }\end{array}$ \\
\hline $\begin{array}{l}\text { Failure func- } \\
\text { tion }\end{array}$ & $\begin{array}{l}\lambda_{1}[t]-\text { is dependence period on failure function for normal state of the first state to the } \\
\text { failure state } \\
\lambda_{2}[t]-\text { is dependence period on failure function for second equipment from normal } \\
\text { state to failure state } \\
\lambda_{3}[t]-\text { is dependence period on failure function from the first equipment in failure state } \\
\text { to both equipment in failure state } \\
\lambda_{4}[t]-\text { is dependence period on failure function from the second equipment in failure } \\
\text { state to both equipment in failure state } \\
\lambda_{5}[t]-\text { is dependence period on failure function from both equipment in normal state } \\
\text { to both equipment in failure state }\end{array}$ & $\begin{array}{l}\lambda_{1}[t]-\text { is dependence period on failure function for the first equipment which is gotten from } \\
\text { normal state to the failure state } \\
\lambda_{2}[t]-\text { is dependence period on failure function for the second equipment and on normal state } \\
\text { for the first and third equipment which is gotten from normal state to the failure state of the } \\
\text { first, normal, second and third equipment } \\
\lambda_{3}[t]-\text { is dependence period on failure function for the third equipment on the operating } \\
\text { state and the first and second equipment on failure function of the first and third equipment } \\
\text { on normal state and the second equipment on failure state. } \\
\text { So on until } \lambda_{4}[t]-\lambda_{12}[t] \text { failure function was taken as in the figure. }\end{array}$ \\
\hline $\begin{array}{l}\text { Repairing } \\
\text { function }\end{array}$ & $\begin{array}{l}\mu_{1}[t]-\text { is dependence period for repairing function of the first equipment after failure } \\
\mu_{2}[t]-\text { is dependence period for repairing function of the second equipment after fail- } \\
\text { ure } \\
\mu_{3}[t]-\text { is dependence period for repairing function of the second equipment and both } \\
\text { equipment after failure } \\
\mu_{4}[t]-\text { is dependence period for repairing function of first equipment and both equip- } \\
\text { ment after failure } \\
\mu_{5}[t]-\text { is dependence period for repairing function of both equipment and both equip- } \\
\text { ment after failure }\end{array}$ & Repairing functions $\mu_{i}[t], i=\overline{1,10}$ were taken same as related failure function. \\
\hline $\begin{array}{l}\text { Weibull distri- } \\
\text { bution }\end{array}$ & 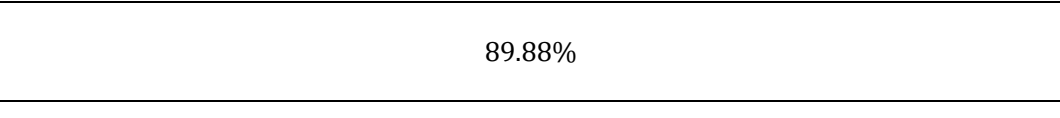 & $\begin{array}{l}\text { Note: Failure function }(\lambda) \text { of three parallel radio communication system, meanings of repair- } \\
\text { ing function }(\mu) \text { were modeled by Weibull distribution law and reliability is not matched with } \\
\text { regular number in this study. }\end{array}$ \\
\hline $\begin{array}{l}\text { Exponential } \\
\text { distribution }\end{array}$ & $69.67 \%$ & $91.77 \%$ \\
\hline $\begin{array}{c}\text { Poisson distri- } \\
\text { bution }\end{array}$ & $89.88 \%$ & $99.12 \%$ \\
\hline
\end{tabular}




\section{doi:10.20944/preprints202106.0073.v1}

Table 1. Analysis for functions of two and three parallel radio communications system and compared results 


\section{References}

1. N. S Temraz. Availability and reliability analysis for system with bivariate Weibull lifetime distribution. International Journal of Scientific \& Engineering Research, Volume 8, Issue 2, February-2017, ISSN:2229-5518.

2. Batzorig Bazargur, Otgonbayar Bataa and Uuganbayar Budjav. Underground mining radio communication system's risk and reliability. Batzorig Bazargur, Journal of Engineering Research and Application www.ijera.com, ISSN: 2248-9622 Vol. 8, Issue 10 (Part -II) Oct 2018, pp 36-39.

3. Batzorig Bazargur, Otgonbayar Bataa. A study of mining communication system reliability model. IFOST-2018, The 13th International Forum on Strategic Technology, CID122_UID3471_PID3702.

4. D.R.Dolas, M.D. Jaybhaye, S.D.Deshmukh. Estimation the system reliability using Weibull distribution, DOI:10.7763/IPEDR. 2014.V75.29.

5. Sigeo Aki and Katuomi Hirano. Lifetime distribution and estimation problems of consecutive-k-out-of-n: F systems, Ann. Inst.Statist.Math. Vol.48, No.1,185-199 (1996.

6. C.D.Lai, Min Xie. A modified Weibull distribution, IEEE TRANSACTIONS ON RELIABILITY, VOL.52, NO.1, MARCH 2003.

7. Ming Dong, Alexandre B.Nassif. Combining modified Weibull distribution models for power system reliability forecast.

8. Maurice Aron, Neila Bhouri, Younes Guessous. Estimating travel time distribution for reliability analysis, transport research arena 2014, Paris. ResearchGate.

9. Mouloud Guemana, Ahmed Hafaifa, Ben Rahmoune Mohamed. Reliability modeling using Rayleigh distribution: Industrial Pump Application. Conference paper June 2016. ResearchGate.

10. Ahmed Hafaifa, Kouzou Abdellah, Guemana Mouloud, Nadji Houdrug. Reliability analysis using Weibull distribution applied to a booster pump used in oil drilling installation. Fifth international scientific conference "Engineering, technologies and systems", TECHSYS-2016, 26-28 May, Plovdiv.

11. M.A.El-Damcese. Reliability equivalence factors of a series-parallel system in Weibull distribution. International Mathematical Forum, 4,2009, no. 19, 941-951.

12. Stylianos Georgiadis and Nicolaos Limnios. Interval reliability for semi-Markov systems in discrete time. Journal de la Societe Francaise de Statistique, Vol. 153 No. 3(2014).

13. Olga Rahneva, Hristo Kiskinov, Ivan Dimitrov and Viktor Matanski. Application of a Weibull cumulative distribution function based on m existing ones to population dynamics. Article - October 2018. International Electronic Journal of Pure and Applied Mathematics, Volume 12, No 1,2018, 111-121. ISSN:1314-0744, DOI:10.12732/iejpam. v12i1.8.

14. S.K.Chauhan and S.C.Malik. Reliability Measures of a series system with Weibull failure laws. International Journal of Statistics and Systems. ISSN 0975-2675 Volume 11, Number 2 (2016), pp.173-186. Research India Publications. http://www.ripublication.com.

15. F.P.A.Coolen, Parametric probability distributions in reliability. Department of Mathematical Sciences, Durham University, Durham, DH1 3LE, UK.

16. Thanh Pham Hong, Nguen Hoang Viet. Power system reliability analysis with distributed generators. Conference paper-October 2007. ResearchGate.

17. Chen Wenhua, Qian Ping, Cui Jie, Ma Zikui, Gao Liang and Liu Juan. Reliability analysis of data only one failure for Exponential distribution. International Journal of Performability Engineering, Vol. 6, No. 3, May 2010, pp.289-296. RAMS Consultants. Printed in India.

18. Zhao Fei, Huang Ning, and Chen Jiaxi. Impact analysis of communication network reliability based on node failure. Proceedings of the 2nd International Symposium on Computer, Communication, Control and Automation (ISCCCA-13). Published by Atlantis Press, Paris, France. (c) The authors, 20130242.

19. Raja Sattiraju, Pratip Chakraborty and Hans D. Schotten. Reliability modeling and analysis of a wireless transmission as a repairable system.

20. Ismihan Bairamov. Joint distribution of a random sample and an order statistic: A new approach with an application in reliability analysis. arXiv:1902.02117v2 [math.ST] 1 Mar 2019. 